\title{
Copper(II) Carboxylate Containing Paddle Wheel Structure: Synthesis and Crystal Structure
}

\author{
ADNAN M. QADIR \\ Department of Chemistry, Collage of Science, Salahaddin University, \\ Erbil 44001, Kurdistan Region, Iraq. \\ *Corresponding author E-mail: aq701998@gmail.com \\ http://dx.doi.org/10.13005/ojc/330249
}

(Received: January 09, 2017; Accepted: March 22, 2017)

\begin{abstract}
A dinuclear copper(II) complex of the type $\left[\mathrm{Cu}_{2}(2-\mathrm{nb})_{4}(\mathrm{MeOH})_{2}\right](2-\mathrm{nb}=2$-nitrobenzoate $)$ has been synthesized and characterized by single crystal $X$-ray diffraction method.The compound belongs to monoclinic space group $P 2_{1} / c$ with $a=19.9374(10), b=21.1404(11), c=7.6533(4)$ $\AA, \alpha=90, \beta=96.817(3), \gamma=90^{\circ}, V=3246.8(3) \AA^{3} Z=4, F(000)=1736.0 .0, D_{c}=1.774 \mathrm{Mg}^{3} \mathrm{~m}^{3}$, $\mu=1.422 \mathrm{~mm}^{-1}$. The $\mathrm{Cu}(\mathrm{II})$ complex is a cocrystal containing two inorganic units. Each $\mathrm{Cu}(\mathrm{II})$ adopted square pyramidal geometry.
\end{abstract}

Keywords: Paddle wheel, Nickel, Synthesis, Carboxylate.

\section{INTRODUCTION}

Generally, most copper(II) carboxylates display the dinuclear paddle-wheel cage structure which consists of two copper centers bridged by four carboxylate molecules and each copper(II) is attached to a neutral ligand. The dimeric copper (II) carboxylates with the formula $\left[\mathrm{Cu}_{2}(\mathrm{RCOO})_{4} \mathrm{~L}_{2}\right]$ are known to contain two or more antiferromagnetically coupled metal centers ${ }^{1-4}$. Dinuclear copper(II) compounds with four syn-syn bridging carboxylato ligands areof special interest due to their fungicidal activity which should arisefrom the unique coordination sphere around central copper(II) ions ${ }^{5}$. Apaddle-wheelstructure type was first reported in 1953 for the case of cupric acetate dehydrate ${ }^{6}$.
Carboxylate ligands can coordinate to metal center in monodenate, bidentate or bridging mode ${ }^{7}$. Copper is a significant transition metal in biology and coordination chemistry ${ }^{8,9}$.Dinuclear copper centres are present in the oxygen breathing protein hemocyanin and in a number of enzymes which have oxidase or oxygenase function ${ }^{10}$. Different members of metalloproteins of the type- 3 with binuclear copper sites are known: hemocyanins, tyrosinase, catechol oxidase with bridging oxygen atoms and cytochrome coxidase with bridging sulfur atoms. In most of these,copper is ligated by histidine and cysteine amino acids ${ }^{11,12}$. In this work, we report synthesis and crystal structure of binuclear $\mathrm{Cu}(\mathrm{II})$ complex containing 2-nitrobenzoic acid. The complex exhibited a paddlewheel structure. 


\section{EXPERIMENTAL}

\section{Synthesis}

A mixture of 2-nitrobenzoic acid $(0.302 \mathrm{~g}$, $2 \mathrm{mmol})$ and $\mathrm{K}_{2} \mathrm{CO}_{3}(0.138 \mathrm{~g}, 1 \mathrm{mmol})$ in $\mathrm{H}_{2} \mathrm{O}(10 \mathrm{ml})$ was added to $\mathrm{Cu}\left(\mathrm{NO}_{3}\right)_{2}(0.188 \mathrm{~g}, 1 \mathrm{mmol})$ in $\mathrm{H}_{2} \mathrm{O}$ $(10 \mathrm{ml})$. The mixture was stirred for 30 minutes. The precipitate formed was filtered and recrystallized from $\mathrm{MeOH}$.

\section{Crystal structure determination}

Single crystal of the title compound with dimensions of $0.44 \mathrm{~mm} \times 0.42 \mathrm{~mm} \times 0.12 \mathrm{~mm}$ was mounted on Bruker APEX-II CCD diffractometer equipped with a graphite-monochromated MoK $\alpha$ radiation $(\lambda=0.71073 \AA$ ) at $100.0(2) \mathrm{K}$. The compound crystallizes in monoclinic space group $\mathrm{P} 2{ }_{1} / \mathrm{c}$ with $\mathrm{a}=19.9374(10), \mathrm{b}=21.1404(11), \mathrm{c}=7.6533(4)$ $\AA \alpha=90, \beta=96.817(3) \gamma=90^{\circ} \mathrm{V}=3246.8(3)$ $\AA^{3} \mathrm{Z}=4, \mathrm{~F}(000)=1736.0 .0, \mathrm{D}_{\mathrm{c}}=1.774 \mathrm{Mg} / \mathrm{m}^{3}$, $\mu=1.422 \mathrm{~mm}^{-1}$. The structure was solved by direct method using XS solution program and refined by least-squares techniques using $X L{ }^{13}$ refinement package. Empirical absorptions were applied to all intensity data. All hydrogen atoms were placed in geometrically calculated positions and allowed to ride on the parent carbon atoms. The full final matrix least square refinement gave $R=0.0356$ and $\mathrm{wR}=0.0805$.

Table 2: Selected Bond Lengths $(\AA \AA)$ and Angles $\left({ }^{\circ}\right)$ For The Complex

\begin{tabular}{|c|c|c|c|}
\hline & \multicolumn{3}{|c|}{ Bond length $(\AA)$} \\
\hline Cu1-01 & $1.9671(10)$ & Cu1'-O1' & $1.9622(10)$ \\
\hline Cu1-O2 & $1.9722(10)$ & Cu1'-O2' & $1.9658(10)$ \\
\hline Cu1-O3 & $1.9670(10)$ & Cu1'-O3' & $1.9586(11)$ \\
\hline Cu1-O4 & $1.9638(10)$ & Cu1'-O4' & $1.9798(10)$ \\
\hline Cu1-O5 & $2.1451(10)$ & Cu1'-O5' & $2.1898(11)$ \\
\hline \multirow[t]{2}{*}{ Cu1-Cu1 ${ }^{1}$} & $2.6210(4)$ & Cu1'-Cu1'2 & $2.6134(4)$ \\
\hline & \multicolumn{3}{|c|}{ Bond angle $\left(^{\circ}\right)$} \\
\hline O5-Cu1-O1 & $97.15(4)$ & O5'-Cu1'-O1' & $88.06(4)$ \\
\hline O5-Cu1-O2 & $93.19(4)$ & O5'-Cu1'-O2' & 93.63(4) \\
\hline O5-Cu1-O3 & $93.60(4)$ & O5'-Cu1'-O3' & $102.69(4)$ \\
\hline O5-Cu1-O4 & $97.78(4)$ & O5'-Cu1'-O4' & $96.84(4)$ \\
\hline O1-Cu1-O3 & $169.18(4)$ & O1'-Cu1'-O3' & $168.88(4)$ \\
\hline O2-Cu1-O4 & $169.02(4)$ & O2'-Cu1'-O4' & $169.51(4)$ \\
\hline
\end{tabular}

Table 1: Crystallographic Data and Refinement for cu (ii) Complex

\section{Crystal data}

Chemical formula

Formula weight

Cell system, space group

a $(\AA)$

b $(\AA)$

c $(\AA)$

$\alpha\left(^{\circ}\right)$

$\beta\left(^{\circ}\right)$

$\gamma\left({ }^{\circ}\right)$

Volume $\left(\AA^{3}\right)$

Z

$\mathrm{Dc}\left(\mathrm{Mg} \mathrm{m}^{-3}\right)$

$\mu\left(\mathrm{mm}^{-1}\right)$

Crystal size ( $\mathrm{mm})$

$2 \Theta$ range for data collection

Index ranges

Reflection collected

Independent

reflections

Data/restraints/parameters

F (000)

Goodness-of-fit on $\mathrm{F}^{2}$

$\mathrm{R} 1[\mathrm{I}>2 \sigma(\mathrm{I})]$

wR2 [I > 2 $\sigma(\mathrm{I})]$

$\mathrm{R} 1$ (all data)

wR2 (all data)

Min. and max. resd.

dens. $\left[e / \AA^{3}\right]$,

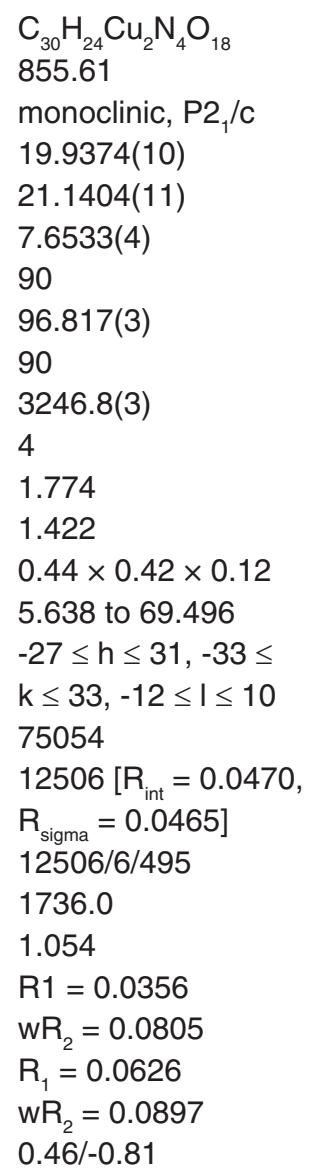

\section{RESULTS AND DISCUSSIONS}

\section{Crystal structure}

Crystal structure of the $\mathrm{Cu}(\mathrm{II})$ complex is depicted in Fig. 1. Crystallographic data and refinement are given in Table-1. Selected bond lengths and angles are given in Table-2.

The title compound belongs to monoclinic $\mathrm{P} 2$ /c space group with four molecules in the unit cell. The $\mathrm{Cu}(\mathrm{II})$ complex is cocrystal with two neutral inorganic components (1 and $\left.\mathbf{1}^{\prime}\right)$. In both components, two $\mathrm{Cu}$ (II) centers are bridged by four carboxylate groups of the four ligands. 


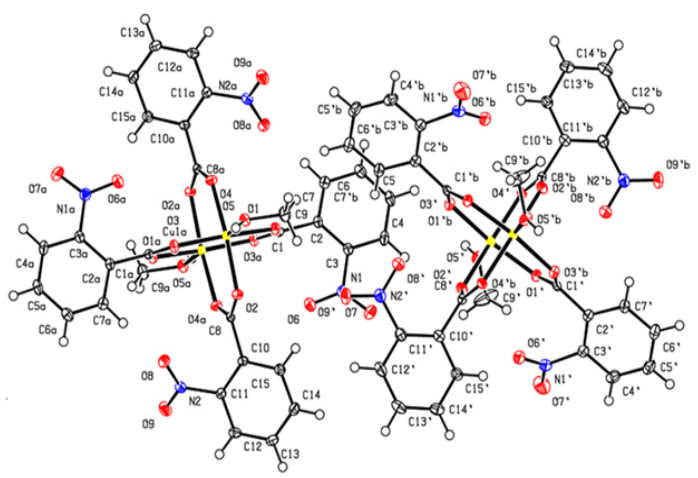

Fig. 1: Molecular structure for the complex

In compound 1, Cu1 has distorted squarepyramidal geometry coordinated by $01,02,03$ and $\mathrm{O} 4$ from four carboxylate molecules in the basal plan and $\mathrm{O} 5$ from $\mathrm{MeOH}$ molecule in the apical position. The angular and structural parameter $(\tau)$ is 0.16 . The bond lengths Cu1-O1,Cu1-O2, Cu1-O3 and Cu1-O4 are 1.9671(10), 1.9722(10), 1.9670(10) and $1.9638(10) \AA$, respectively, while the apical bond length Cu1-O5 is 2.1451(10)A. The values are in agreement with bond distances for other binuclear $\mathrm{Cu}(\mathrm{II})$ complex. The bond angles O5-Cu1-O range from $93.19(4)$ to $97.78(4)^{\circ}$. The Cu1-Cu1 ${ }^{1}$ bond distance is $2.6210(4) \AA$ in the dinuclear unit.

In compound 1', Cu1' has almost regular square-pyramidal geometry $(\tau=0.0105)$ coordinated by $\mathrm{O}_{1}$ ',O2',O3' and $\mathrm{O} 4$ ' from four carboxylate ligands in the basal plan and $\mathrm{O}^{\prime}$ from $\mathrm{MeOH}$ molecule in the apical position. TheCu1'-O $\mathrm{O}_{\text {carboxylate }}$ bond lengths range $1.9586(11)$ from to $1.9798(10) \AA$, while the

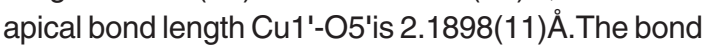
angles O5'-Cu1'-O1',O5'-Cu1'-O2', O5'-Cu1'-O3' and O5'-Cu1'-O4'are 88.06(4), 93.63(4), 102.69(4) and $96.84(4)^{\circ}$, respectively. The Cu1'-Cu1'2 bond distance is $2.6210(4) \AA$.

\section{Supplementary material}

CCDC 1420202 contains the supplementary crystallographicdata for this paper. These data can be obtained free ofcharge at www.ccdc.cam. ac.uk/conts/retrieving.html or fromthe Cambridge Crystallographic Data Centre (CCDC), 12 UnionRoad, Cambridge CB2 1EZ, UK (Fax: +44-1223-336033; email: deposit@ ccdc.cam.ac.uk or www:http://www. ccdc.cam.ac.uk).

\section{REFERENCE}

1. Chadjistamatis, I.; Terzis, A.; Raptopoulou, C.P. and Perlepes, S.P.Inorg. Chem. Commun. 2003,6,1365 .

2. Baranwal, B.P.; Das,S.S. and Singh, P.Synth. React. Inorg. Met. Org. Chem.1998,28, 1689.

3. Baran, E.J.; Etcheverry, S.B.; Torre M.H. and Kremer, E.Polyhedron1994,13,1859.

4. Campbell and Haw, J.F.Inorg Chem1998,27,3706.

5. Kasuni, M.; nik,K.G.; Egedin, P. and Golobi, A.Acta Chim. Slov.201057, 350.

6. Niekerk, J.N.V. and Schoening, F.R.L.Acta Cryst.1953,6,227.
7. Qadir, A.M. Asian J. Chem.2013, 25, 8829.

8. Thomas, A.M.; Nethaji, M.; Mahadevan,S. and Chakravarty, A.R. Inorg. Biochem.2003,94,171.

9. Zhang, L.; Niu, S.Y.; Jin, J.; Sun, L.P.; Yang G.D. and Yie, L.Chem. J. Chin. Universities2009,30, 236.

10. Bullock, G.; Hartstock,F.W. and Thomps, L.Can. J . Chem.1983,61, 57.

11. Solomon, E.I.; Sundaram U.M. and Machonkin, T.E.Chem. Rev. 1996, 96, 2563.

12. Borghi, E. and Solari, P.L. J. Synchrotron Rad.2005, 12, 102.

13. Shldrick, M.Acta crystallogr. A2008,64, 112. 